\title{
5-Year data analysis of patients following abdominal wall endometrioma surgery
}

\author{
Tahere Khamechian', Javad Alizargar ${ }^{2}$ and Tahere Mazoochi ${ }^{*^{*}}$
}

\begin{abstract}
Background: Endometriosis is a disorder in which an ectopic endometrial tissue grows outside the uterine cavity. The ectopic endometrium embedded in the subcutaneous fatty layer and the muscles of abdominal wall is called as abdominal wall endometriosis (AWE). AWE is a rare condition; however, it is usually known to develop along with previous surgical scars. Caesarean section and hysterectomy are considered to be commonly associated with the development of AWE.

Methods: We evaluated the data of the patients who underwent AWE surgery between March 2009 and March 2014.

Results: The mean age of the patients was 32.5 years. We found a previous history of caesarean section in all of the patients. The most frequent symptoms of the patients were abdominal mass sensation and abdominal pain. Invasion of endometriosis to fat layer, fascia, muscular layer, and peritoneum was recorded. Three masses were located within the scar regions.
\end{abstract}

Conclusions: We can conclude that there is a high prevalence of caesarean sections among the women with AWE.

Keywords: Endometrioma, Abdominal wall endometriosis, Scar endometriosis

\section{Background}

Endometriosis was first described by an Austrian pathologist, Karl Freiherr von Rokitansky in 1860 who referred to the disease as adenomyoma [1]. Endometriosis is a rare condition in which ectopic endometrial tissue grows outside the uterine cavity and responds to hormonal stimuli [2]. Although its prevalence in adult women is not completely known, it is said to occur in $5 \%-10 \%$ [3]. Although it is more common in pelvic regions such as the ovaries, posterior cul-de-sac, ligaments of the uterus, pelvic peritoneum, and rectovaginal septum [4], it can also be extrapelvic. The extrapelvic occurrence of endometriosis is rare and it occurs more commonly in abdominal wall followed by umbilicus, vulva, appendix, ileum, hernia sac, and colon [5]. It is known to develop spontaneously [6] and is usually found near or at the site of scars of surgeries like hysterectomies, caesarean sections, laparoscopies, tubal ligations, and episiotomies [4,7]. These sites propose the "iatrogenic direct implantation

\footnotetext{
*Correspondence: jaz_1365@yahoo.com

${ }^{3}$ Gametogenesis Research Center, Kashan University of Medical Sciences, Kashan, I.R Iran

Full list of author information is available at the end of the article
}

theory", which emphasizes on the implantation of the escaped endometrial cells caused by the surgery into the surgical wound [8].

The ectopic endometrium is embedded in subcutaneous fatty layer and muscles of abdominal wall in abdominal wall endometriosis (AWE) [9]. AWE is considered very rare with the overall prevalence of around $0.01-1 \%$ after caesarean section [10]. In addition, AWE is often mistaken with some surgical conditions like abscess, lipoma or incisional hernia [11]. Although manifestations of endometriosis may range from dysmenorrhea to even bowel perforation [12], the most prevalent clinical feature of endometriosis includes a painful mass with a cyclic pain that exacerbates with menstruation [4].

The present study presents the features of AWE in a five-year experience of surgeons from Shahid Beheshti Hospital. It describes the patients' characteristics and manifestations of the disease.

\section{Methods}

After obtaining written informed consent, the data of the patients who underwent surgery for AWE between 
March 2009 and March 2014; including age, parity, related past medical history, chief complaint, the exact site of AWE, and any information gained after the surgery were entered in the study. This study has complete approval by the institutional review board of Kashan University of Medical Sciences.

\section{Results}

Histological confirmation of endometrioma is based on detecting at least two of the three following features: endometrial stroma, endometrial like glands and hemosiderin pigment [10]. After histopathological confirmation (Figure 1), the data of 30 patients who underwent AWE surgery were entered in our study. All the patients had at least two features of endometrioma. Table 1 summarizes the characteristics of the patients with abdominal wall endometriosis. The age of the patients ranged from 23 to 67 years. The mean age of the patients was $32.5 \pm 8.24$ years. Their number of parities ranged from one to four. We found a previous history of caesarean section in all of the patients. Eleven patients (36.6\%) had a single caesarean section. Fourteen patients $(46.7 \%)$ had two caesarean sections and five (16.7\%) had three caesarean sections. Eight patients (26.7\%) had surgeries other than caesarean section. These surgeries include one myomectomy, three hysterectomies, one tubalectomy, and three appendectomies. All patients had a notable mass as a presenting symptom. Other than the mass, 24 patients (80\%) experienced pain, among whom 14 patients (46.7\%) experienced cyclic pain. Two patients (6.7\%) had dyspareunia, three (10\%) had dysmenorrhea, and one (3.3\%) had bleeding as presenting symptoms. Four patients did not have any symptoms and AWE was discovered during the caesarean sections. The mean duration of symptoms was $12.7 \pm 10.44$ months, ranging from three to forty-five months. The mean time between the previous surgery and diagnosis of AWE was $30.5 \pm 12.65$ months. In 28 patients (93.3\%), the ultrasonography was used to diagnose AWE, computed tomography (CT) scan and magnetic resonance imaging (MRI) were used in five (16.6\%)
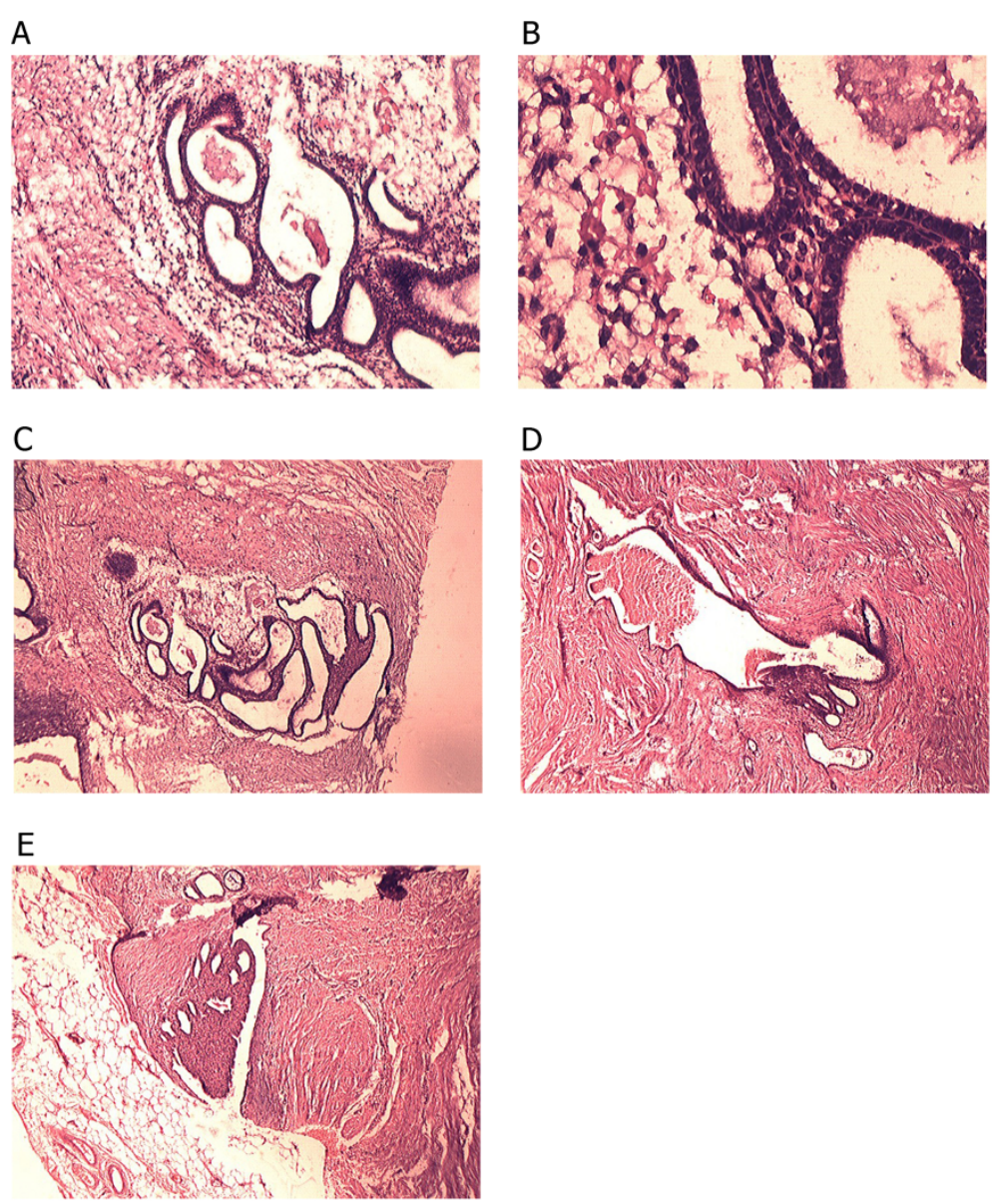

Figure 1 Histopathological characteristics of endometriosis in different tissue types. A: Endometrial strauma and glands in fatty connective tissue (X10). B: Endometrial strauma and glands in fatty connective tissue (X40). C: Endometrial strauma and glands in fibro-connective tissue (X10). D: Endometrial strauma and glands in muscular tissue (X10). E: Endometrial strauma and glands in muscular tissue adjacent to fatty layer (X10). 
Table 1 Characteristics of the patients with abdominal wall endometriosis

\begin{tabular}{|c|c|c|c|c|}
\hline & $\mathbf{n}$ & $\%$ & Range & Mean +/- SD \\
\hline Age & & & $23-67$ & $32.5 \pm 8.24$ \\
\hline Parity & & & $0-4$ & 2 \\
\hline One CS & 11 & 36.6 & & \\
\hline Two CS & 14 & 46.7 & & \\
\hline Three CS & 5 & 16.7 & & \\
\hline \multicolumn{5}{|l|}{ Surgeries other than CS } \\
\hline Myomectomy & 1 & 3.3 & & \\
\hline Hysterectomy & 3 & 10 & & \\
\hline Tubalectomy & 1 & 3.3 & & \\
\hline Appendectomy & 3 & 10 & & \\
\hline \multicolumn{5}{|l|}{ Presenting symptom } \\
\hline Mass & 30 & 100 & & \\
\hline Pain (noncyclic) & 10 & 33.3 & & \\
\hline Pain (cyclic) & 14 & 46.7 & & \\
\hline Dyspareunia & 2 & 6.7 & & \\
\hline Dysmenorrhea & 3 & 10 & & \\
\hline Bleeding & 1 & 3.3 & & \\
\hline Duration of symptoms (months) & & & $3-45$ & $12.77 \pm 10.44$ \\
\hline Asymptomatic period (months) & & & $2-53$ & $30.5 \pm 12.65$ \\
\hline \multicolumn{5}{|l|}{ Diagnosing tool } \\
\hline Ultrasonography & 28 & 93.3 & & \\
\hline$C T$ & 5 & 16.6 & & \\
\hline MRI & 2 & 6.6 & & \\
\hline Single mass & 27 & 90 & & \\
\hline Two masses & 3 & 10 & & \\
\hline Accurate diagnosis & 19 & 63.3 & & \\
\hline Wrong diagnosis & 11 & 36.7 & & \\
\hline \multicolumn{5}{|l|}{ Location of the mass } \\
\hline Under the scar & 18 & 60 & & \\
\hline In the scar & 3 & 10 & & \\
\hline Far from the scar & 9 & 30 & & \\
\hline Diameter of the mass $(\mathrm{cm})$ & & & $1-6$ & $2.59 \pm 1.21$ \\
\hline
\end{tabular}

CS: Caesarean Section.

and two $(6.6 \%)$ patients, respectively. Twenty-seven patients $(90 \%)$ had a single mass, whereas, three $(10 \%)$ had two masses at the time of diagnosis. In nineteen patients (63.3\%), the initial diagnosis was AWE, whereas abdominal wall tumour was diagnosed in four patients (13.3\%), incisional hernia in three (10\%) cases, suture granuloma in two cases (6.7\%), and inguinal hernia and desmoid tumour each in one case (3.3\%). The location of the masses was in or under the scar of the previous surgery in 21 patients (70\%) (in three cases the mass was located in the scar), hypochondrium away from the scar and umbilicus each in four cases (13.3\%), and groin region in one case (3.3\%).
The mean diameter of the masses was $2.59 \pm 1.21 \mathrm{~cm}$, ranging between $1 \mathrm{~cm}$ and $6 \mathrm{~cm}$. Nine cases (30\%) had a mass in the fat tissue, fourteen (46.7\%) in muscle tissue, eleven (36.7\%) in the fascia of the abdomen muscles, ten $(33.3 \%)$ in the omentum, and one (3.3\%) in the dermis. Hematoma and necrosis were observed in one (3.3\%) and two patients (6.7\%), respectively. No case of malignancy was reported among our study patients. All the patients underwent follow-up tests and one patient was diagnosed with a recurred mass after six months, which was removed with clear margins.

\section{Discussion}

Caesarean section and hysterectomy are considered to be commonly associated with AWE, and the surgical scar of the caesarean section is the most common site for extra pelvic endometriosis known as caesarean scar endometriosis with the incidence of $0.07 \%-0.47 \%$ [4]. In the current study, all the patients with AWE had a prior history of caesarean section and some patients had another gynaecological surgery such as hysterectomy besides caesarean section. In our study, the majority of patients had one or two caesarean sections.

There are two theories that are more accepted for the cause of AWE: transport theory and metaplasia theory. The transport theory explains that direct inoculation or transport of the endometrial tissue into the surgical scars or adjacent tissues during the surgery is responsible for AWE. In metaplasia theory, primitive pleuropotential mesenchymal cells that have gone under differentiation metaplasia are said to cause AWE. Alternative theories like lymphatic or haematogenic dissemination and cell immunity change theory are among the other proposed theories $[8,10]$. The fact that all the patients of our study had undergone a cesarean section, and some had other gynecological surgeries may be in favor of transport theory. This theory might explain that endometrial tissues can be iatrogenically transported into the abdominal wall or into the scars of the surgery. Although the presence of endometrial tissues in the abdominal wall can be explained with this theory, some other features of endometriosis, like why the endometrial tissues can survive and proliferate in the new sites cannot be explained with the transport theory.

Mass sensation, pain, dysmenorrhea and bleeding are among the symptoms of endometriosis. Although the cycle symptoms may be pathognomonic of endometriosis, the symptoms can be non-cyclic, too. Endometriosis can be categorized as a steroid-dependant disease [13]. It is known that oestrogens can trigger the development of endometriotic lesions. Endometrial cells can be stimulated with oestrogen and proliferate until they become symptomatic. The oestrogen can be further produced in the endometrial lesions by aromatase activity 
[14]. All the patients in our study had symptoms of abdominal mass sensation. Additionally, $46.7 \%$ of them experienced cyclic pain and 33.3\% experienced noncyclic pain. Dysmenorrhea and bleeding were the presenting symptoms in $10 \%$ and $3.3 \%$ of the patients, respectively. Ultrasonography is mentioned as the most frequently used technique for diagnosing AWE and we used this diagnostic tool in $93.3 \%$ of the patients. CT scan and MRI were the least used methods.

Not all of the endometriosis patients had cyclic symptoms. The diagnosis of this disease might be challenging and several differential diagnoses might exist for a mass in the abdominal wall, including desmoid tumour, fibrosis, suture granuloma, fat necrosis, nodular fasciitis and primary or metastatic malignancies lesions [15]. Although the history of previous gynaecological surgeries might be helpful and leading us to AWE, the definite diagnosis of endometriosis might be possible only after the surgery and removal of the mass and pathological evaluations. Using of fine needle aspiration cytology (FNAC) can be helpful before the surgery and can be used for determining all three criterion of endometriosis [15], but it was not performed in our study.

The presence of AWE in the surgery scar is quite infrequent. The series of one, five, and six scar endometriosis had been reported earlier $[11,16,17]$. We only found ten percent of the masses of the patients ( 3 masses) were located within the scars of the previous caesarean sections.

Although the risk of malignancy transformation of endometriosis is not known and less than $1 \%$ of endometriosis patients are reported to develop associated neoplasms, the most common type is clear-cell carcinoma. This neoplasm has 5-year survival of $80 \%$ [8]. Although there are some reports of clear-cell carcinoma associated with AWE [18], there was none in our study.

\section{Conclusion}

In conclusion, it is worth saying that although abdominal wall endometriosis is a rare disorder, it can occur after gynaecological surgeries and caesarean sections especially near or within the scars. As caesarean section rates are becoming more frequent, and there is a high prevalence of caesarean section among women with AWE, we may encounter higher rates of this uncommon entity in the future.

\section{Competing interests}

The authors declare that they have no competing interests.

\section{Authors' contributions}

JA analyzed and interpreted the patient data regarding the pathological disease and the preparation of paraffin sections. TK performed the histological examination, participated in the design of the study and performed the statistical analysis, and was a contributor in writing the manuscript. TM conceived of the study, and participated in its design and coordination and helped to draft the manuscript. All authors read and approved the final manuscript.

\section{Authors' information}

After medical school, Javad has conducted research in a wide range of medical fields. He began to participate in the Student Research Committee of Kashan University Of Medical Sciences (SRC of KAUMS) beginning the first year of medical school. He participated as a lecturer in SRC and different congresses and seminars and was chosen to be the Distinct Researcher of KAUMS. He has a range of publications in the departments of Pathology, Physiology, Social Sciences, Health, Infectious Disease, Pediatrics, and Surgery and Emergency Medicine of KAUMS. He contributed to data collecting, data analysis, writing, and editing research results. He also likes to design studies and write proposals in various areas of medicine. Working as a general physician in different clinics and emergency rooms helped him evaluate a variety of alternative medications and gave him the opportunity to observe rare cases.

\section{Acknowledgements}

We gratefully acknowledge the contribution of all the staff of obstetrics and gynaecology department of Shahid-Beheshti hospital in gathering the data.

\section{Author details}

${ }^{1}$ Anatomical Sciences Research Center, Kashan University of Medical Sciences, Kashan, I.R Iran. ${ }^{2}$ Student Research Committee, Kashan University of Medical Sciences, Kashan, I.R. Iran. ${ }^{3}$ Gametogenesis Research Center, Kashan University of Medical Sciences, Kashan, I.R Iran.

Received: 19 June 2014 Accepted: 17 November 2014 Published online: 05 December 2014

\section{References}

1. Benagiano G, Brosens I: The history of endometriosis: identifying the disease. Hum Reprod 1991, 6(7):963-968 [PMCID: PMC3394553].

2. Williams HE, Barsky S, Storino W: Umbilical endometrioma (silent type). Arch Dermatol 1976, 112(10):1435-1436 [PMID 962339].

3. Giudice LC, Kao LC: Endometriosis. Lancet 2004, 364:1789.

4. Bektaş H, Bilsel Y, Sari YS, Ersöz F, Koç O, Deniz M, Boran B, Hug GE: Abdominal wall endometrioma; a 10-year experience and brief review of the literature. J Surg Res 2010, 164(1):e77-e81. [PMID 20855082] doi: 10.1016/j.jss.

5. García-Santos EP, Muñoz-Atienza V, Sánchez-García S, Puerto-Puerto A, Ruescas-García FJ, Manzanares-Campillo MC, Martínez-de Paz F, Padilla-Valverde D, Vitón-Herrero R, González-López L: Endometriosis de localización extraovárica. Nuestra casuística en 10 años. Progresos de Obstetricia y Ginecología 2014, 57(3):117-120. doi: 10.1016/j.pog.2013.10.003.

6. Ideyi SC, Schein M, Niazi M, Gerst PH: Spontaneous endometriosis of the abdominal wall. Dig Surg 2003, 20(3):246-248. [PMID 12759505] doi:10.1159/000070392

7. Marsden NJ, Wilson-Jones N: Scar endometriosis: a rare skin lesion presenting to the plastic surgeon. J Plast Reconstr Aesthet Surg 2013, 66(4):e111-e113. [PMID 23369738] doi: 10.1016/j.bjps.

8. Ding $Y$, Zhu J: A retrospective review of abdominal wall endometriosis in Shanghai, China. I J Gynecol Obstet 2013, 121(1):41-44.

9. Savelli L, Manuzzi L, Di Donato N, Salfi N, Trivella G, Ceccaroni M, Seracchioli R: Endometriosis of the abdominal wall: ultrasonographic and Doppler characteristics. Ultrasound Obstet Gynecol 2012, 39(3):336-340. [PMID 21793086] doi:10.1002/uog.10052.

10. Dwivedi AJ, Agrawal SN, Silva YJ: Abdominal wall endometriomas. Dig Dis Sci 2002, 47:456-461 [PMID 11855568].

11. Goel P, Devi L, Tandon R, Saha PK, Dalal A: Scar endometriosis - a series of six patients. Int J Surg 2011, 9(1):39-40. [PMID 20804870] doi: 10.1016/j.ijsu.

12. García JAF, Bañosa SR, Garcíab MEJ, Juradoa MA, Fernandezc GB: Acute abdomen as the first clinical manifestation of endometriosis. Progresos de Obstetricia y Ginecología 2013, 56(6):322-325. doi:10.1016/j.pog.2012.10.004.

13. Lattuada D, Somigliana E, Viganò P, Candiani M, Pardi G, Di Blasio AM: Genetics of endometriosis: a role for the progesterone receptor gene polymorphism PROGINS? Clin Endocrinol (Oxf) 2004, 61:190-194.

14. Bulun SE, Imir G, Utsunomyia H, Thung S, Gurates B, Tamura M, Lin Z: Aromatase in endometriosis and uterine leiomyomata. J Steroid Biochem Mol Biol 2005, 95:57-62. 
15. Pathan ZA, Dinesh U, Rao R: Scar endometriosis. J Cytol 2010, 27:106-108.

16. Nissotakis C, Zouros E, Revelos K, Sakorafas GH: Abdominal wall endometrioma: a case report and review of the literature. ARON J 2010, 91(6):730-745.

17. Akdemir A, Akman L, Tore Yavuzsen H, Zekioglu O: Clinical features of the patients with endometriosis on the cesarean scar. Kaohsiung J Med Sci 2014, 30(10):541-543.

18. Yan Y, Li I, Guo J, Zheng Y, Liu Q: Malignant transformation of an endometriotic lesion derived from an abdominal wall scar. Int I Gynecol Obstet 2011, 115(2):202-203.

doi:10.1186/s12905-014-0151-4

Cite this article as: Khamechian et al: 5-Year data analysis of patients following abdominal wall endometrioma surgery. BMC Women's Health 2014 14:151

\section{Submit your next manuscript to BioMed Central and take full advantage of:}

- Convenient online submission

- Thorough peer review

- No space constraints or color figure charges

- Immediate publication on acceptance

- Inclusion in PubMed, CAS, Scopus and Google Scholar

- Research which is freely available for redistribution 